\title{
Home: International Perspectives on Culture, Identity, and Belonging
}

Kusenbach, Margarethe \& Paulsen, Krista E. (red)

Peter Lang Academic, 2013

Antologin Home: International Perspectives on Culture, Identity, and Belonging låter oss blicka in i hemmets vardag. Genom empiriska studier förflyttas läsaren till så skilda platser som generationsboenden i Ryssland, livet hos nyinflyttad medelklass i en lantlig Londonförort, vardagen på ungdomshem i Sverige, hemlösas liv och relationer i Las Vegas, och livet i Assisted Living-boende i USA, bland andra. Samtidigt som hemmet rör det innersta av våra mänskliga liv är det (kanske just därför) en central komponent $i$ det sociala arbetets praktik. För mig som socionom och doktorand i socialt arbete är läsningen präglad av antologins användbarhet i min disciplin, men den har relevans för långt fler praktiker inom det socialvetenskapliga fältet. Socionomen kan precis som polisen, läraren eller juristen läsa boken med intresse, både för de empiriska exemplens och det teoretiska bidragets skull.

Med bokens bredd vill redaktörerna Margarethe Kusenbach och Krista E. Paulsen bidra med kunskap om hemmet från olika discipliners perspektiv. Och visst finns det något för alla. Antologin innehåller 14 kapitel av 16 författare från sociologi, statsvetenskap, antropologi, gerontologi och visual art. Den presenterar studier från sju olika länder i Nordamerika och Europa (det internationella perspektivet är egentligen ett västvärldsperspektiv). De miljöer studierna behandlar är både intima rum (familj och hushåll) och offentliga rum (gator och grannskap).

I det inledande kapitlet binder redaktörerna samman bokens empiriska studier samtidigt som de diskuterar hemmet som teoretiskt begrepp. Samtliga studier har sin utgångspunkt $\mathrm{i}$ att hemmet är en central företeelse i människans liv, samt att hemmet teoretiskt bör förstås som ett skapat fenomen. Hem görs genom att individer eller grupper tillskriver platser mening. Denna teoretiska utgångspunkt kommer till liv genom att de empiriska studierna ger läsaren inblick i många olika sorters hem, också sådana platser vi kanske inte vanligtvis ser som hem. Läsaren märker att hemmet ovillkorligen är omgärdat med starka normativa idéer som påverkar våra uppfattningar om de platser där människor lever sina liv.

Bokens 13 empiriska kapitel är uppdelade i tre delar. Familjen och hushållet behandlas i antologins första och andra del, medan den tredje och sista delen behandlar bostadsområden, orter och städer. I första delen står förhållandet mellan hemmet som materialitet och hemmet som idé i fokus. Samtliga studier i denna del är skrivna av forskare verksamma i USA. Strom och Greenbaum undersöker hur husägare som står inför vräkningshot resonerar kring huslån och husägandet som ideal och praktik i finanskrisens USA. I kapitlet Modeling Home: Ideals of Residential Life in Builders' 
Show Houses utforskas hur utformningen av visningshus speglar vilka köpare man vill locka. Författaren menar exempelvis att samtliga visningshus i studien var inredda på sätt som reflekterar medelklassens smak och preferenser. Kapitel tre behandlar i kontrast till detta hur människor som lever i hemlöshet arrangerar sin vardag för att en känsla av hem ska infinna sig, både i form av fysisk lokalitet och emotionell trygghet. Första delens sista kapitel utmanar idén om hemmet som något som finns på bara en plats när författaren genom fotografier och text återger berättelser om bikulturella erfarenheter.

I bokens andra del tar antologin steget utanför USA. Här fortsätter arbetet med att utmana föreställningar, och merparten av kapitlen ägnas åt hemmiljöer som är långt från de bilder av hemmet som antologins inledande kapitel bygger på, inte minst det om visningshus. Om inte socionomen vaknar till vid läsning av första delen, så bör hon göra det nu. Författarna visar hur människor gör hem, hur de skapar ett hem i de lokaliteter de bebor, och vilken roll sociala praktiker och materialiteter har i detta görande. I sitt kapitel om särskilda ungdomshem i Sverige menar Wästerfors att det personliga, avskildhet, och integritet är centrala komponenter i hemgörande praktiker. På ungdomshemmet, liksom på de Assisted living-boende för äldre i USA som Warren och Williams undersöker, arrangerar ungdomarna sina rum så att de reflekterar en personlighet som de själva - inte personalen - väljer att tillskriva sig. När det är möjligt skapar ungdomarna rum av avskildhet, exempelvis genom att vägra åka hem över helgen vilket gör att de får stanna kvar på boendet mer eller mindre ensamma. På liknande sätt försöker de vuxna barn i Zaviscas studie i Ryssland, som ofrivilligt bor tillsammans med sina föräldrar och/eller föräldrarnas föräldrar, möblera den alltför trånga lägenheten så att någon form av privatliv och avskildhet kan råda. Det sista kapitlet i antologins andra del inriktas på beslutsprocesser och de val (eller brist på val) familjer står inför vid flytt till nytt boende.

I bokens tredje och avslutande del vidgas perspektivet till grannskap och offentliga rum. I samtliga kapitel är det tillhörighet (belonging) och invånarnas känslor inför sitt hem och bostadsområde som står i fokus. De inflyttades upplevelser behandlas både i Watts studie av en engelsk villaförort, och i Christmanns studie i ett socialt utsatt innerstadsområde i Tyskland. I Place Feelings and Life Stories in Florida Mobile Home Communities visar Kusenbach hur känslor inför (det stigmatiserade) hemmet relaterar till bostaden i sig men också till hemmets status i förhållande till den omgivande sociala miljön. Boken avslutas med Binken och Bloklands kapitel om möten i det offentliga stadsrummet och hur interaktion med obekanta både skapar och inte skapar en känsla av tillhörighet.

Jag tog mig an läsningen av Home: International Perspectives on Culture, Identity, and Belonging utifrån frågan om boken kan vara något för socialt arbete som praktik och forskningsområde. Jag menar att den är det. Livet i hemmet har ovillkorligen 
en plats i det sociala arbetets praktik, oavsett om hemmet finns på en institution, på andra sidan jorden, på flera platser, eller kanske inte existerar alls i fysisk materiell form. Samtidigt som människors boplatser är en central komponent i praktiskt socialt arbete reflekterar vi sällan över hemmet som socialt fenomen. Denna bok är därför ett välkommet tillskott i socionomens bokhylla.

Det går inte att förneka att det stundtals känns omständligt att läsa en bok bestående av tretton separata empiriska studier. Det är som att man börjar om alltför många gånger. Å andra sidan behöver man inte läsa en antologi från pärm till pärm. Men för den som gör just detta får bokens teoretiska innehåll en djupare dimension. De tretton empiriska kapitlen levandegör de teoretiska perspektiv som presenteras i redaktörernas inledande kapitel. Att sammanfoga studierna är ett effektivt sätt att illustrera mångfalden i de olika lokaliteter och praktiker som kan förstås som hem. På ett konkret sätt åskådliggör empirin hemmet som social och skapad företeelse, laddat med värden, normer och mening. Hem skapas och förstås i relation till våra föreställningar om det goda hemmet. En förståelse för dynamiken i dessa hem-görande praktiker är viktig kunskap.

Socionomen tar med sig fler lärdomar från läsningen. Vetskap om att hem inte nödvändigtvis behöver förstås i termer av fysisk bostad, även om de två ofta sammanfaller i praktiken, är tillämplig i socialt arbete. "Home starts by bringing some space under control", skriver antropologen Mary Douglas, vilket antologins redaktörer uppmärksammar. De skriver att upplevelsen av kontroll, autonomi, trygghet, samt möjligheten att vara sig själv är själva essensen av vad det innebär att känna sig hemma. Redaktörerna konstaterar också att såväl definitioner av hemmet som känslor associerade med hemmet ofta antas ha en positiv laddning. Samtidigt vet inte minst socialarbetaren att det i praktiken kan se annorlunda ut, och boken kan ge nya perspektiv på återkommande frågor inom socialt arbete. Den som exempelvis är utsatt för våld eller förtryck i sin bostad känner sig troligtvis inte lugn och trygg där. Om inte boningen är förknippad med trygghet, var finns då hemmet? Hur ser hem-görande praktiker ut för den som befinner sig på flykt? Om familjen berövar en medlem möjligheten att vara sig själv och att uttrycka sin identitet, är denna familjemedlem då hemma i den gemensamma bostaden? Att tänka kring hemmet som teoretiskt begrepp och social konstruktion är en ypperlig hjälp för socialarbetaren som vill vidga sin syn på människans liv och varande i och utanför hemmet. Den här antologin ger god hjälp på vägen.

\section{Christel Avendal}

Socionom, doktorand vid Socialhögskolan, Lunds universitet 